\title{
Trends in dietary fat and fatty acid intakes and related food sources among Chinese adults: a longitudinal study from the China Health and Nutrition Survey (1997-2011)
}

\author{
Xin Shen ${ }^{1}$, Aiping Fang ${ }^{2}$, Jingiing He ${ }^{1}$, Ziqi Liu ${ }^{1}$, Meihan Guo ${ }^{1}$, Rong Gao ${ }^{1}$ and Keji Li ${ }^{1, *}$ \\ ${ }^{1}$ Department of Nutrition and Food Hygiene, School of Public Health, Peking University, No. 38 Xueyuan Road, \\ Haidian District, Beijing 100191, People's Republic of China: ${ }^{2}$ Department of Nutrition, School of Public Health, \\ Sun Yat-sen University, Guangzhou, People's Republic of China
}

Submitted 25 November 2016: Final revision received 29 May 2017: Accepted 19 June 2017: First published online 9 August 2017

\begin{abstract}
Objective: Few studies have evaluated the intake trends of fatty acids in China. The present study aimed to describe the profile of longitudinal dietary fat and fatty acid intakes and their related food sources in Chinese adults.

Design: A longitudinal study using data from the China Health and Nutrition Survey (1997-2011) was conducted. Dietary intake was estimated using $24 \mathrm{~h}$ recalls combined with a food inventory for three consecutive days. Linear mixed models were used to calculate the adjusted mean intake values.

Setting: Urban and rural communities in nine provinces (autonomous regions), China.

Subjects: Adults ( $n$ 19475; 9420 men and 10055 women).

Results: Fat intake among men in 1997 was $73.4 \mathrm{~g} / \mathrm{d}(28.1 \%$ of total energy (\%TE)), while in 2011 it increased to $86.3 \mathrm{~g} / \mathrm{d}(33.2 \% \mathrm{TE})$. Similarly, for women, this intake increased from $62.7 \mathrm{~g} / \mathrm{d}(28.4 \% \mathrm{TE})$ in 1997 to $74.1 \mathrm{~g} / \mathrm{d}(33.7 \% \mathrm{TE})$ in 2011. Energy intake from SFA grew from 6.8 to $7 \cdot 6 \%$ TE for both sexes. PUFA intake increased from 18.4 to $22.5 \mathrm{~g} / \mathrm{d}$ for men and from 15.7 to $19.7 \mathrm{~g} / \mathrm{d}$ for women, and was above $6 \% \mathrm{TE}$ in all survey periods. Intakes of $18: 2$ and 18:3 fatty acids showed significant upward trends in both sexes. Participants consumed less animal fats and more vegetable oils, with more PUFA intake and less energy from SFA. EPA and DHA intakes fluctuated around $20 \mathrm{mg} / \mathrm{d}$.

Conclusions: Fatty acid intakes and profile in Chinese adults are different from those reported in other countries.
\end{abstract}

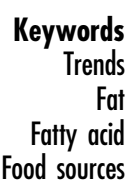

Fat has a crucial role in membrane structures, the immune system and brain development ${ }^{(1,2)}$. Dietary fat is one of the most important macronutrients: it provides energy $(38 \mathrm{~kJ} / \mathrm{g}$ $(9 \mathrm{kcal} / \mathrm{g})$ ); supplies two essential fatty acids, i.e. $\alpha$-linolenic acid (18:3n-3) and linoleic acid (18:2n-6); and facilitates the absorption of lipid-soluble vitamins ${ }^{(3)}$. On the other hand, it is widely accepted that high intake of some specific dietary fats is associated with several chronic diseases such as CVD, obesity, cancers and type 2 diabetes mellitus ${ }^{(4-6)}$. It has also been indicated that the amount of specific types of dietary fat, i.e. SFA, MUFA and PUFA, is more notable than the total amount of dietary fat in the relationship with the risk of these diseases ${ }^{(7,8)}$. An expert panel of the WHO concluded that there is convincing evidence that replacing SFA with PUFA decreases the risk of CHD, and possible evidence of a relationship between PUFA intake and reduced risk of diabetes mellitus ${ }^{(9)}$.
The WHO and FAO have established recommendations for dietary fat intakes to decrease the burden of chronic diseases caused by excessive intakes of specific dietary fatty acids worldwide: for total dietary fat, $15-35 \%$ of total energy (\%TE); for SFA, an upper limit of $10 \% \mathrm{TE}$; and 6-11\%TE for PUFA ${ }^{(9)}$. Various countries such as the USA, the UK, China and Japan have all developed their own national guidelines ${ }^{(10-13)}$. Chinese dietary reference intakes suggest a total fat intake of 20-30\%TE and SFA intake of $<10 \%$ TE for adults ${ }^{(12)}$.

The growth rate of China's gross domestic product continued the great momentum maintained since the implementation of the country's reform and opening-up policy. As the economy developed, Chinese people, especially the ones living in urban areas with higher household incomes, transformed their 'traditional' dietary pattern to be 'westernized $^{,(14-16)}$. The Chinese traditional diet consists mainly of 
cereals, tubers and vegetables, with small to moderate intakes of animal foods, high intakes of carbohydrate and dietary fibre and low intake of fat, while the 'westernized' diet tends to contain more animal foods and refined plant foods accompanied with high fat and protein intakes and low dietary fibre intake ${ }^{(4,17,18)}$. In recent years, transformation of the dietary pattern from 'traditional' low-fat to 'westernized' high-fat was thought to be an aetiological factor in the prevalence of chronic diseases in China ${ }^{(19-22)}$.

However, scant research has evaluated longitudinal trends of fatty acid intakes in Chinese adults over the past decades, particularly with regard to examining the changing profile of dietary fatty acids ${ }^{(23)}$. The present study aimed to report the trends of total fat, SFA, MUFA, PUFA and essential fatty acid intakes and their food sources in Chinese adults using the long-term follow-up data from year 1997 to 2011 from the China Health and Nutrition Survey (CHNS).

\section{Methods}

\section{Study design}

The CHNS are an ongoing series of longitudinal household surveys established in 1989 and followed-up in 1991, 1993, 1997, 2000, 2004, 2006, 2009 and 2011. The design of the CHNS has been previously described in detail elsewhere ${ }^{(24,25)}$. Eight provinces joined the survey from 1989 to 1997, including Liaoning (replaced by Heilongjiang in 1997), Shandong, Jiangsu, Henan, Hubei, Hunan, Guangxi and Guizhou. In 2000, Liaoning rejoined the survey and in 2011, three municipal cities (Beijing, Shanghai, Chongqing) were added. A multistage, random cluster approach was used to draw the sample surveyed in each province. Four counties (one low-, two middle- and one high-income county, defined on the basis of per capita income) and two cities (a large city, usually the provincial capital, and a randomly selected smaller lowerincome city) were selected from each province using a weighted sampling method. Two urban and two suburban communities were randomly selected in cities. One community in the capital city and three rural villages were randomly chosen in counties. Twenty households were then randomly selected within each community ${ }^{(25)}$. All individuals in each household were interviewed.

\section{Data collection}

The survey data were obtained mainly from three aspects: a questionnaire survey, a physical examination and a diet recall. Demographic and lifestyle information such as survey year, age, sex, ethnic origin, stratum, smoking status, physical activity level, education level and work status were obtained through a questionnaire. Participants' body weight, height, waist and hip circumferences and blood pressure were measured by well-trained investigators, following a standard protocol with calibrated equipment. BMI was calculated as weight/height ${ }^{2}\left(\mathrm{~kg} / \mathrm{m}^{2}\right)$. Diet recall data at individual level while food inventory data at household level were collectively obtained on three consecutive days (randomly allocated to start from Monday to Sunday). The same procedure was followed during all nine survey periods for collecting dietary recall data. An urbanization index was measured that represents the change in twelve dimensions (including population density, economic activity, traditional markets, modern markets, communications, transportation infrastructure, sanitation, housing, diversity, education, health infrastructure and social services) at community level ${ }^{(26,27)}$. The information on food composition data and food codes of 1989, 1991 and 1993 was unable to be extracted from Chinese authorities. In the present study, we used the survey data from 1997 to 2011 only, and excluded participants who reported implausible total energy or total fat intake (the upper and lower $1 \%$ of the intake) and those younger than 18 years old.

\section{Dietary assessment}

The measurement of individuals' dietary intake in CHNS is a combination of two parts: three consecutive $24 \mathrm{~h}$ dietary recalls at the individual level and a household-level food inventory weighing performed over the same three days, which were randomly allocated from Monday to Sunday. The three consecutive days of $24 \mathrm{~h}$ recall dietary data were collected by trained nutritionists who recorded amounts, types and place of all the food items consumed. To determine the food consumption at household level, the change in available food was weighed and recorded from the beginning to the end of each survey. With oil and condiments as an example, we converted household survey data into individual intake by calculating the percentage of the oil and condiments from the home inventory that each member consumed by the ratio of his or her energy intake to the energy intake of all family members. The nutrient intake amounts from consumed foods were further found using an expanded and updated ongoing database: the China Food Composition Tables ${ }^{(28-30)}$.

According to the classification rules of the China Food Composition Tables, we further divided food items into eight groups, including meat and meat products, poultry and poultry products, dairy and dairy products, eggs and egg products, fish, shellfish and molluscs, animal oils, vegetable oils and others. The information on each individual's daily fatty acid intake, such as SFA, MUFA and PUFA, was converted from grams per $100 \mathrm{~g}$ of food to grams per actual weight of food consumed. The total weight of a certain food group was calculated as the sum of raw weights of the edible parts of all foods in this group.

\section{Statistical analysis}

Data analyses were performed using the statistical software package SAS version 9.2. Fatty acids were presented in the unit of percentage of total energy (\%TE) to compare 
with the China and WHO recommendations. Linear mixed-effect models were used to calculate the adjusted mean values of total fat, protein, carbohydrate, SFA, MUFA, PUFA, EPA, DHA, 18:1, 18:2 and 18:3 fatty acids (adjusted for age, urbanization index and total energy intake). Adjusted means and se were used to describe the variables in each survey round. The changes in nutrient intakes over the survey period were characterized by linear trend tests. Trends in fatty acid intakes were conducted stratified by sex, when considering the different energy intakes and nutrient requirements.

\section{Results}

Demographic information is presented in Table 1. A total of 19475 adults (9420 men and 10055 women) were included in our study. Slightly more than half of the participants were women in each survey round. The mean age ranged from 43.0 to $50 \cdot 8$ years and from $44 \cdot 1$ to $50 \cdot 6$ years for men and women, respectively. The urbanization index increased by approximately $37 \%$ as per capita gross domestic product increased sevenfold over the survey period.

Adjusted mean intakes of fatty acids and their main food sources, stratified by sex, among Chinese adults older than 18 years are shown in Tables 2-4.

\section{Total fat intake and food sources}

Compared with 1997, dietary energy intake was lower in 2011 ( $P$ for trend $<0 \cdot 0001$ ) while both intake and energy proportion of total fat were higher $(P$ for trend $<0 \cdot 0001$; Table 1). In 2011 nearly half of the participants, $47 \cdot 3 \%$ of men and $48.5 \%$ of women, consumed dietary fat $>35 \% \mathrm{TE}$ (Fig. 1). Vegetable oils were the main source of total fat, providing about $40 \%$ or more (Table 4), and their mean daily intake was 26 and $29 \%$ greater for men and women, respectively, over time. Meanwhile, animal oil intakes showed a downward trend ( $P$ for trend $<0 \cdot 0001$; Table 3 ) and provided about one-tenth or less of total fat (Table 4). The ratio of animal to plant protein ( $P$ for trend $<0.0001$; Table 1) was higher in 2011 than in 1997, which is in line with more animal food consumption (Table 3 ). Meat and meat products were the most consumed animal foods (Table 3), which provided about one-quarter of total fat in both sexes (Table 4). Daily intakes of eggs, fish and seafood and dairy foods were low and provided minor amounts of fat (Tables 3 and 4).

\section{SFA intake and food sources}

In 2011, SFA intake in men and women was slightly higher than SFA intake in 1997. Energy from SFA also showed a fluctuating and increasing trend, from $6 \cdot 8$ to $7 \cdot 6 \% \mathrm{TE}$ for both sexes ( $P$ for trend $<0 \cdot 0001$; Table 2 ). The percentage of participants with SFA intake $>10 \%$ TE was nearly $10 \%$ higher over the survey period to reach approximately $22 \%$ of the study population in 2011 (Fig. 1). The percentage of
SFA from animal sources (animal oils and meat food) decreased by about 7 to $8 \%$, while that from vegetable oils showed an upward trend in the early half of the survey period and a downward trend in the later half to provide about one-third of total SFA (Table 4).

\section{MUFA intake and food sources}

The trend of MUFA intake was similar to that of SFA. The energy from MUFA was 2\% higher in 2011 than in 1997 for both sexes (Table 2). The mean intake of $18: 1$ fatty acid, the major source of MUFA, was about $3 \mathrm{~g} / \mathrm{d}$ higher in 2011 than in 1997 ( $P$ for trend <0.0001; Table 2). With the increasing intake of MUFA, MUFA from animal oils almost halved, while that from vegetable oils increased by nearly $10 \%$ ( $P$ for trend $<0 \cdot 0001$; Table 4 ).

\section{PUFA intake and food sources}

Table 2 shows that the mean PUFA intake in our study population was about $4 \mathrm{~g} / \mathrm{d}$ higher in 2011 than in 1997. The percentage of energy from PUFA, with an upward trend, was from 7 to $9 \% \mathrm{TE}$ and always within the range of $6-11 \% \mathrm{TE}$ (the WHO recommendation) during the whole survey period. Animal oils, meat and meat products and vegetable oils were the top three food groups providing PUFA (Table 4). The percentage of PUFA from vegetable oils was higher than that from animal oils and meat and meat products ( $P$ for trend $<0 \cdot 0001$; Table 4). During the survey period, the mean intake of EPA plus DHA fluctuated around $20 \mathrm{mg} / \mathrm{d}, 18$ to $27 \mathrm{mg} / \mathrm{d}$ for men and 15 to $24 \mathrm{mg} / \mathrm{d}$ for women (Table 2). About $90 \%$ of EPA and DHA was obtained from fish, shellfish and molluscs (Table 4). Significant upward trends in 18:2 and $18: 3$ fatty acid intakes were observed; in 2011, the intake of $18: 2$ or $18: 3$ fatty acid was about 3 or $0.5 \mathrm{~g} / \mathrm{d}$ higher than in 1997, respectively, for both sexes ( $P$ for trend <0.0001; Table 2). The percentage of 18:2 and 18:3 fatty acids from vegetable oils, which accounts for about or more than half of their amounts, was larger than that from animal sources (animal oils, meat and poultry foods; Table 4). The mean percentage of energy from 18:3 in 2011 was 0.5 to $0 \cdot 8 \%$ TE higher than that in 1997 for both sexes.

\section{Discussion}

To our knowledge, few researches have focused on the trends of fat and fatty acid intakes in a representative population $^{(31-35)}$, especially in Chinese who underwent a rapid transition in food pattern and disease profile during the past decades. Our study demonstrated that from 1997 to 2011, Chinese adults consumed more vegetable oils, but less animal fats, resulting in more MUFA and PUFA intakes while the percentage of energy from SFA was of low level. They consumed less fish and seafood, resulting in very low EPA and DHA intakes of about $20 \mathrm{mg} / \mathrm{d}$. These data show that the dietary fat and fatty acids in the Chinese diet are different from those reported in Western countries ${ }^{(36-39)}$ 
Table 1 General characteristics of participating Chinese adults aged 18 years or above $(n 19475)$ in each survey round by sex, China Health and Nutrition Survey, 1997-2011*

\begin{tabular}{|c|c|c|c|c|c|c|c|c|c|c|c|c|}
\hline & \multicolumn{2}{|c|}{1997} & \multicolumn{2}{|c|}{2000} & \multicolumn{2}{|c|}{2004} & \multicolumn{2}{|c|}{2006} & \multicolumn{2}{|c|}{2009} & \multicolumn{2}{|c|}{2011} \\
\hline & Mean & SE & Mean & SE & Mean & SE & Mean & SE & Mean & SE & Mean & SE \\
\hline \multicolumn{13}{|l|}{ Men } \\
\hline$n$ & \multicolumn{2}{|c|}{3439} & \multicolumn{2}{|c|}{3618} & \multicolumn{2}{|c|}{3600} & \multicolumn{2}{|c|}{3655} & \multicolumn{2}{|c|}{3918} & \multicolumn{2}{|c|}{4746} \\
\hline Age (years) & 43.0 & 0.3 & $45 \cdot 0$ & 0.3 & 47.6 & 0.3 & 48.9 & 0.3 & $49 \cdot 7$ & 0.2 & $50 \cdot 8$ & 0.2 \\
\hline Urbanization index & 53.4 & 0.3 & 59.9 & 0.3 & $64 \cdot 2$ & 0.3 & $65 \cdot 3$ & 0.3 & $67 \cdot 7$ & 0.3 & 73.5 & 0.3 \\
\hline Energy $(\mathrm{MJ} / \mathrm{d}) \dagger$ & $10 \cdot 4$ & 0.05 & $10 \cdot 2$ & 0.04 & $10 \cdot 1$ & 0.04 & $10 \cdot 0$ & 0.04 & 9.9 & 0.04 & $9 \cdot 2$ & 0.04 \\
\hline \multicolumn{13}{|l|}{ Total fat $\neq$} \\
\hline$g / d$ & 73.4 & 0.5 & 79.7 & 0.4 & $79 \cdot 3$ & 0.4 & $80 \cdot 8$ & 0.4 & 83.7 & 0.4 & $86 \cdot 3$ & 0.4 \\
\hline$\%$ TE & $28 \cdot 1$ & 0.2 & 29.9 & 0.2 & 29.7 & 0.2 & 30.4 & 0.2 & 31.5 & 0.2 & 33.2 & 0.2 \\
\hline \multicolumn{13}{|l|}{ Protein $\ddagger$} \\
\hline$g / d$ & 73.4 & 0.3 & 71.9 & 0.3 & 71.4 & 0.3 & $71 \cdot 0$ & 0.2 & $72 \cdot 1$ & 0.2 & 73.5 & 0.2 \\
\hline$\%$ TE & 12.5 & 0.04 & $12 \cdot 2$ & 0.04 & $12 \cdot 1$ & 0.04 & $12 \cdot 0$ & 0.04 & $12 \cdot 2$ & 0.04 & $12 \cdot 6$ & 0.04 \\
\hline \multicolumn{13}{|l|}{ Carbohydrate } \\
\hline $\mathrm{g} / \mathrm{d}$ & 348.0 & $1 \cdot 2$ & 334.8 & $1 \cdot 1$ & 352.5 & 1.0 & $347 \cdot 3$ & 1.0 & 341.8 & 0.9 & $336 \cdot 0$ & 0.9 \\
\hline$\%$ TE & 58.2 & 0.2 & $56 \cdot 6$ & 0.2 & 59.5 & 0.2 & $58 \cdot 6$ & 0.2 & $57 \cdot 6$ & 0.2 & $55 \cdot 9$ & 0.2 \\
\hline Animal protein:plant proteinł & 0.53 & 0.01 & 0.53 & 0.01 & 0.51 & 0.01 & 0.55 & 0.01 & 0.60 & 0.01 & 0.64 & 0.01 \\
\hline \multicolumn{13}{|l|}{ Women } \\
\hline$n$ & \multicolumn{2}{|c|}{3539} & \multicolumn{2}{|c|}{3923} & \multicolumn{2}{|c|}{3800} & \multicolumn{2}{|c|}{3914} & \multicolumn{2}{|c|}{4148} & \multicolumn{2}{|c|}{5046} \\
\hline Age (years) & 44.1 & 0.3 & $45 \cdot 3$ & 0.2 & 48.1 & 0.2 & 49.4 & 0.2 & $50 \cdot 0$ & 0.2 & 50.6 & 0.2 \\
\hline Urbanization index & $54 \cdot 1$ & 0.3 & $60 \cdot 3$ & 0.3 & $64 \cdot 6$ & 0.3 & 65.6 & 0.3 & $68 \cdot 1$ & 0.3 & 73.5 & 0.3 \\
\hline Energy $(\mathrm{MJ} / \mathrm{d}) \dagger$ & $8 \cdot 8$ & 0.04 & 8.6 & 0.03 & $8 \cdot 6$ & 0.04 & $8 \cdot 4$ & 0.04 & 8.3 & 0.03 & $7 \cdot 8$ & 0.03 \\
\hline \multicolumn{13}{|l|}{ Total fatł } \\
\hline$g / d$ & $62 \cdot 7$ & 0.4 & 67.5 & 0.4 & $67 \cdot 7$ & 0.4 & $69 \cdot 4$ & 0.4 & 71.6 & 0.3 & $74 \cdot 1$ & 0.3 \\
\hline$\%$ TE & 28.4 & 0.2 & 30.0 & 0.1 & $30 \cdot 1$ & 0.2 & $31 \cdot 0$ & 0.2 & 31.9 & 0.2 & 33.7 & 0.2 \\
\hline \multicolumn{13}{|l|}{ Protein $\ddagger$} \\
\hline$g / d$ & $62 \cdot 7$ & 0.2 & 61.6 & 0.2 & $61 \cdot 2$ & 0.2 & $61 \cdot 3$ & 0.2 & $61 \cdot 6$ & 0.2 & 63.0 & 0.2 \\
\hline$\%$ TE & $12 \cdot 6$ & 0.04 & $12 \cdot 4$ & 0.04 & $12 \cdot 3$ & 0.04 & $12 \cdot 3$ & 0.04 & $12 \cdot 4$ & 0.04 & $12 \cdot 8$ & 0.04 \\
\hline \multicolumn{13}{|l|}{ Carbohydrate $\ddagger$} \\
\hline$g / d$ & 297.4 & 0.9 & $287 \cdot 6$ & 0.8 & 298.5 & 0.8 & 294.5 & 0.8 & 289.9 & 0.8 & 285.4 & 0.7 \\
\hline$\%$ TE & $59 \cdot 0$ & 0.2 & 57.5 & 0.2 & $59 \cdot 6$ & 0.2 & $58 \cdot 7$ & 0.2 & 57.8 & 0.2 & $56 \cdot 2$ & 0.2 \\
\hline Animal protein:plant protein $\ddagger$ & 0.52 & 0.01 & 0.52 & 0.01 & 0.50 & 0.01 & 0.56 & 0.01 & 0.57 & 0.01 & 0.61 & 0.01 \\
\hline Per capita GDP (\$US) & 77 & & 94 & & 14 & & 20 & & 37 & & 54 & \\
\hline
\end{tabular}

$\%$ TE, percentage of total energy intake; GDP, gross domestic product.

${ }^{*} P$ for trend $<0.0001$ for all variables.

†Adjusted for age and urbanization index; $1 \mathrm{MJ}=1000 \mathrm{~kJ}, 1 \mathrm{kcal}=4 \cdot 184 \mathrm{~kJ}$.

$\ddagger$ Adjusted for age, urbanization index and total energy intake.

and maritime nations such as Japan ${ }^{(40)}$. It is then required to re-examine the relationship, observed in Western countries $^{(41-43)}$, of dietary fat with the more prevalent chronic diseases that have been observed over the past decades in China ${ }^{(44,45)}$. Based on the present diet data, the dietary fat is dominated by vegetable oils, and it should be analysed if Chinese people suffer a different risk of chronic diseases to Westerners who consume more SFA and marine $n-3$ fatty acids. These data also imply that Chinese people depend mostly on the de novo synthesis of EPA and DHA from $\alpha$ linolenic acid in their body. Hence it may be questionable from the viewpoint of dietary availability and scientific rationality to recommend Chinese people to take the same amount of DHA and EPA as peoples of other countries.

As reported elsewhere ${ }^{(23,46,47)}$, the similar trend is found that total fat intakes are higher after than before the period of fast economic growth in China. Compared with the situation in Japan during its economic boom of the $1960 \mathrm{~s}$ and 1970s, the Japanese also had a rapid increase in fat intake, which reached 58g/d and 25\%TE in 1973 and fluctuated around this value thereafter ${ }^{(48,49)}$. In contrast, average fat intakes in our study kept increasing over the whole survey period and reached a level of more than $33 \% \mathrm{TE}$, approaching that of Europeans and Americans ${ }^{(38,50)}$.

Several publications have reported average fatty acid intakes in populations from different countries ${ }^{(31,34,51)}$. A recent review demonstrated that only two of twenty-four European countries had SFA intake below 10\%TE and about half of these countries had PUFA intake below $6 \% \mathrm{TE}$, and SFA and PUFA intakes and food patterns in Europe had slightly changed during the past 20-25 years $^{(33)}$. The National Health and Nutrition Examination Survey (NHANES) reported that Americans have kept their mean intakes of SFA above 10\%TE and of PUFA above $6 \% \mathrm{TE}$ in past decades ${ }^{(50)}$. In contrast, recent data from Japan, Bangladesh, South Korea and India reported their mean SFA intakes were below $10 \% \mathrm{TE}^{(34,52,53)}$. The explanation for this difference between Western and Asian countries might be the different food sources of dietary fat. For instance, Chinese consume their fat primarily from vegetable oils and secondly from animal oils and meat foods; on the contrary, Westerners ingest fat primarily from dairy, butter and meat food, and secondly from vegetable oils ${ }^{(32,33,36,54)}$. Vegetable oils were reported as 
Table 2 Adjusted mean intakes of fatty acids among Chinese adults aged 18 years or above $(n 19475)$ in each survey round by sex, China Health and Nutrition Survey, 1997-2011*

\begin{tabular}{|c|c|c|c|c|c|c|c|c|c|c|c|c|}
\hline & \multicolumn{2}{|c|}{1997} & \multicolumn{2}{|c|}{2000} & \multicolumn{2}{|c|}{2004} & \multicolumn{2}{|c|}{2006} & \multicolumn{2}{|c|}{2009} & \multicolumn{2}{|c|}{2011} \\
\hline & Mean & SE & Mean & SE & Mean & SE & Mean & SE & Mean & SE & Mean & SE \\
\hline \multicolumn{13}{|l|}{ Men } \\
\hline \multicolumn{13}{|l|}{ SFA } \\
\hline$g / d$ & $17 \cdot 8$ & 0.2 & $19 \cdot 6$ & 0.1 & $18 \cdot 2$ & 0.1 & $19 \cdot 0$ & 0.1 & 19.7 & 0.1 & $19 \cdot 6$ & 0.1 \\
\hline$\%$ TE & $6 \cdot 8$ & 0.05 & $7 \cdot 4$ & 0.05 & $6 \cdot 8$ & 0.05 & $7 \cdot 2$ & 0.05 & $7 \cdot 4$ & 0.04 & $7 \cdot 6$ & 0.05 \\
\hline \multicolumn{13}{|l|}{ MUFA } \\
\hline $\mathrm{g} / \mathrm{d}$ & 28.0 & 0.2 & 30.5 & 0.2 & $30 \cdot 7$ & 0.2 & 31.6 & 0.2 & $32 \cdot 2$ & 0.2 & 33.2 & 0.2 \\
\hline$\%$ TE & $10 \cdot 7$ & 0.1 & 11.4 & 0.1 & 11.4 & 0.1 & 11.8 & 0.1 & $12 \cdot 1$ & 0.1 & $12 \cdot 8$ & 0.1 \\
\hline \multicolumn{13}{|l|}{ PUFA } \\
\hline$g / d$ & 18.4 & 0.2 & 20.5 & 0.2 & 20.4 & 0.2 & $20 \cdot 0$ & 0.2 & $21 \cdot 7$ & 0.2 & 22.5 & 0.2 \\
\hline$\%$ TE & $7 \cdot 1$ & 0.1 & $7 \cdot 7$ & 0.1 & $7 \cdot 7$ & 0.1 & 7.6 & 0.1 & 8.1 & 0.1 & 8.7 & 0.1 \\
\hline \multicolumn{13}{|l|}{ EPA } \\
\hline $\mathrm{mg} / \mathrm{d}$ & $8 \cdot 2$ & 0.0004 & $9 \cdot 3$ & 0.0006 & $10 \cdot 5$ & 0.0005 & $11 \cdot 8$ & 0.001 & 11.5 & 0.0008 & $15 \cdot 2$ & 0.001 \\
\hline DHA† & $10 \cdot 3$ & 0.001 & 8.6 & 0.001 & $10 \cdot 0$ & 0.001 & 14.9 & 0.001 & 12.5 & 0.001 & 11.7 & 0.001 \\
\hline \multicolumn{13}{|l|}{$18: 1$} \\
\hline \multicolumn{13}{|l|}{$\begin{array}{r}g / d \\
18: 2\end{array}$} \\
\hline \multicolumn{13}{|l|}{$g / d$} \\
\hline \multicolumn{13}{|l|}{$18: 3$} \\
\hline \multirow{2}{*}{\multicolumn{13}{|c|}{$\begin{array}{r}\mathrm{g} / \mathrm{d} \\
\text { Women }\end{array}$}} \\
\hline & & & & & & & & & & & & \\
\hline \multicolumn{13}{|l|}{ SFA } \\
\hline$g / d$ & $15 \cdot 1$ & 0.1 & $16 \cdot 6$ & 0.1 & $15 \cdot 5$ & 0.1 & $16 \cdot 3$ & 0.1 & $16 \cdot 7$ & 0.1 & $16 \cdot 6$ & 0.1 \\
\hline$\%$ TE & $6 \cdot 8$ & 0.05 & 7.4 & 0.05 & 6.9 & 0.04 & $7 \cdot 3$ & 0.05 & 7.5 & 0.04 & $7 \cdot 6$ & 0.04 \\
\hline \multicolumn{13}{|l|}{ MUFA } \\
\hline$g / d$ & 23.8 & 0.2 & $25 \cdot 6$ & 0.2 & $26 \cdot 0$ & 0.2 & $27 \cdot 0$ & 0.2 & $27 \cdot 3$ & 0.2 & $28 \cdot 2$ & 0.2 \\
\hline$\%$ TE & $10 \cdot 8$ & 0.1 & 11.3 & 0.1 & 11.5 & 0.1 & $12 \cdot 0$ & 0.1 & $12 \cdot 2$ & 0.1 & $12 \cdot 8$ & 0.1 \\
\hline \multicolumn{13}{|l|}{ PUFA } \\
\hline$g / d$ & $15 \cdot 7$ & 0.2 & 17.4 & 0.2 & 17.5 & 0.2 & $17 \cdot 3$ & 0.1 & $18 \cdot 7$ & 0.2 & 19.7 & 0.1 \\
\hline$\%$ TE & $7 \cdot 2$ & 0.1 & $7 \cdot 8$ & 0.1 & $7 \cdot 8$ & 0.1 & $7 \cdot 8$ & 0.1 & $8 \cdot 3$ & 0.1 & $9 \cdot 0$ & 0.1 \\
\hline \multicolumn{13}{|l|}{ EPA } \\
\hline \multirow{2}{*}{\multicolumn{13}{|c|}{$\begin{array}{c}\mathrm{mg} / \mathrm{d} \\
\text { DHAt }\end{array}$}} \\
\hline & & & & & & & & & & & & \\
\hline \multicolumn{13}{|l|}{$\mathrm{mg} / \mathrm{d}$} \\
\hline $\mathrm{g} / \mathrm{d}$ & $21 \cdot 6$ & 0.2 & $23 \cdot 2$ & 0.2 & $23 \cdot 1$ & 0.2 & $23 \cdot 6$ & 0.2 & $24 \cdot 0$ & 0.2 & 24.7 & 0.1 \\
\hline $18: 2$ & & & & & & & & & & & & \\
\hline$g / d$ & $14 \cdot 0$ & 0.2 & $15 \cdot 5$ & 0.2 & $15 \cdot 3$ & 0.1 & $15 \cdot 0$ & 0.1 & $16 \cdot 3$ & 0.1 & $17 \cdot 2$ & 0.1 \\
\hline $\begin{array}{r}18: 3 \\
\mathrm{~g} / \mathrm{d}\end{array}$ & 1.3 & ? & 1. & ? 0 & 17 & & 17 & 0 & 18 & ? & 17 & ? \\
\hline g/u & 1.0 & $0.0<$ & 1.5 & 0.02 & 1.7 & 0.02 & 1.1 & 0.02 & 1.0 & 0.02 & 1.1 & $0.0<$ \\
\hline
\end{tabular}

$\%$ TE, percentage of total energy intake.

${ }^{*}$ Adjusted for age, urbanization index and total energy intake. Significant trend in each subgroup (except DHA) across the survey years, $P<0.0001$.

$\dagger P$ for trend $<0.05$ for men and $<0.001$ for women

showing an increased consumption over time in China and India ${ }^{(52,55,56)}$, the mean intake of vegetable oils in European countries also showed a growing trend in the past, while the percentage of vegetable oils in total edible oils reached a higher level in China than in these countries (approximately $85 \% v$. less than 50\%) ${ }^{(38,57)}$

The very low intakes of EPA and DHA reported here are in line with the result of the Minnesota Heart Survey ${ }^{(39)}$. During the whole survey period, mean intakes of EPA plus DHA remained below $30 \mathrm{mg} / \mathrm{d}$, which is far less than the reported intakes of 80 to $1189 \mathrm{mg} / \mathrm{d}$ in Europeans ${ }^{(3,38,40)}$, 90 to $150 \mathrm{mg} / \mathrm{d}$ in Americans ${ }^{(39,58)}$, nearly $1000 \mathrm{mg} / \mathrm{d}$ in Japanese $^{(40)}$ and the FAO/WHO's acceptable macronutrient distribution range of $0 \cdot 25-2 \mathrm{~g} / \mathrm{d}^{(9)}$. Such low intakes of EPA and DHA imply that Chinese people have to synthesize them de novo from $\alpha$-linolenic acid to meet the physiological requirement. The main source of EPA and DHA is fish, shellfish and molluscs; as compared with other animal foods, consumption of these are very low in Chinese, accounting for no more than $20 \%$ of the total intake of animal foods according to data from the China Nation Bureau of Statistics over the past two decades ${ }^{(57)}$. The present data on EPA, DHA and fish and seafood consumption reflect the Chinese long-term and traditional dietary pattern. In considering the unknown efficiency of EPA and DHA synthesis in the body of Chinese people, which might undergo a metabolic adaptation to the habitual dietary pattern which can be up-regulated possibly ${ }^{(59-61)}$, caution should be taken before recommending to Chinese people an allowance of dietary DHA and EPA, as per FAO/ $\mathrm{WHO}^{(9)}$, European $^{(3)}$ and American ${ }^{(10)}$ guidelines, without available and sufficient fish and seafood supply and 
Table 3 Daily intakes $(\mathrm{g} / \mathrm{d})$ of main food sources of fatty acids among participating Chinese adults aged 18 years or above $(n 19475)$ in each survey round by sex, China Health and Nutrition Survey, 1997-2011*

\begin{tabular}{|c|c|c|c|c|c|c|c|c|c|c|c|c|}
\hline & \multicolumn{2}{|c|}{1997} & \multicolumn{2}{|c|}{2000} & \multicolumn{2}{|c|}{2004} & \multicolumn{2}{|c|}{2006} & \multicolumn{2}{|c|}{2009} & \multicolumn{2}{|c|}{2011} \\
\hline & Mean & SE & Mean & $\mathrm{SE}$ & Mean & $\mathrm{SE}$ & Mean & SE & Mean & SE & Mean & SE \\
\hline \multicolumn{13}{|l|}{ Men } \\
\hline Meat and meat products $†$ & $57 \cdot 8$ & 0.9 & $60 \cdot 5$ & 0.9 & $56 \cdot 8$ & 0.8 & $58 \cdot 8$ & 0.8 & $60 \cdot 4$ & 0.8 & $60 \cdot 8$ & 0.8 \\
\hline Poultry and poultry products $\ddagger$ & 9.7 & 0.4 & 9.8 & 0.4 & 9.9 & 0.4 & 9.0 & 0.4 & $12 \cdot 1$ & 0.4 & 13.8 & 0.4 \\
\hline Dairy and dairy products $\ddagger$ & $12 \cdot 2$ & 0.6 & $16 \cdot 2$ & 0.9 & $18 \cdot 0$ & 0.9 & $14 \cdot 2$ & 0.8 & $13 \cdot 1$ & 0.8 & 21.9 & 1.0 \\
\hline Eggs and egg products $\ddagger$ & $25 \cdot 1$ & 0.6 & $26 \cdot 4$ & 0.6 & $24 \cdot 8$ & 0.5 & $27 \cdot 0$ & 0.5 & 28.4 & 0.5 & $28 \cdot 7$ & 0.5 \\
\hline Fish, shellfish and molluscs $\ddagger$ & 23.7 & 0.6 & $20 \cdot 2$ & 0.5 & $21 \cdot 2$ & 0.6 & 21.6 & 0.6 & $22 \cdot 9$ & 0.6 & $21 \cdot 1$ & 0.6 \\
\hline Animal oilsł & $7 \cdot 7$ & 0.3 & 8.6 & 0.3 & $6 \cdot \overline{7}$ & 0.2 & 6.5 & 0.2 & 6.1 & 0.2 & $5 \cdot 1$ & 0.2 \\
\hline Vegetable oilsł & 28.9 & 0.4 & 31.8 & 0.4 & $35 \cdot 7$ & 0.4 & 34.1 & 0.4 & $36 \cdot 4$ & 0.4 & $36 \cdot 4$ & 0.3 \\
\hline \multicolumn{13}{|l|}{ Women } \\
\hline Meat and meat products $\S$ & $47 \cdot 1$ & 0.7 & 49.2 & 0.7 & $46 \cdot 8$ & 0.7 & 48.9 & 0.7 & $49 \cdot 1$ & 0.7 & 47.9 & 0.6 \\
\hline Poultry and poultry products $\ddagger$ & 8.6 & 0.4 & 8.3 & 0.4 & 8.0 & 0.4 & $8 \cdot 3$ & 0.4 & $9 \cdot 8$ & 0.4 & 11.9 & 0.4 \\
\hline Dairy and dairy products $\ddagger$ & 11.4 & 0.5 & $17 \cdot 1$ & 0.8 & $19 \cdot 7$ & 0.9 & $16 \cdot 8$ & 0.8 & $15 \cdot 3$ & 0.8 & $26 \cdot 0$ & 1.0 \\
\hline Eggs and egg products $\ddagger$ & $24 \cdot 1$ & 0.5 & 24.5 & 0.5 & $23 \cdot 6$ & 0.5 & $25 \cdot 2$ & 0.5 & $26 \cdot 8$ & 0.5 & $26 \cdot 9$ & 0.4 \\
\hline Fish, shellfish and molluscs $†$ & $20 \cdot 3$ & 0.5 & $17 \cdot 4$ & 0.5 & $17 \cdot 9$ & 0.5 & $19 \cdot 1$ & 0.6 & 18.7 & 0.5 & 18.6 & 0.5 \\
\hline Animal oilsł & $6 \cdot 4$ & 0.3 & $7 \cdot 4$ & 0.2 & $5 \cdot 6$ & 0.2 & 5.4 & 0.2 & $5 \cdot 1$ & 0.2 & $4 \cdot 1$ & 0.1 \\
\hline Vegetable oilsł & $25 \cdot 0$ & 0.4 & $27 \cdot 2$ & 0.3 & $30 \cdot 7$ & 0.3 & $29 \cdot 6$ & 0.3 & $32 \cdot 0$ & 0.3 & $32 \cdot 2$ & 0.3 \\
\hline
\end{tabular}

${ }^{*}$ Adjusted for age, urbanization index and total energy intake.

$\dagger P$ for trend $<0.001$.

$\ddagger P$ for trend $<0.0001$

$\S P$ for trend $<0.05$.

scientific evidence. Generally, over the period 1997-2011, with 5\%TE addition of total fat, Chinese people ingested a smaller amount of energy from SFA with slow growth and a greater amount of energy from PUFA with modest growth in comparison with Europeans and Americans. Chinese people had very low intakes of EPA and DHA in comparison with Europeans, Americans and Japanese.

High dietary fat intake is thought to be a risk factor for chronic diseases ${ }^{(3,62,63)}$. The increase in incidence of chronic diseases in China over the past decades is partly attributed to the changing amount of dietary fat ${ }^{(64)}$. However, this suggestion overlooked the evidence that the type and food sources of fat consumed are more meaningful than the total fat amount in the relationship of dietary fat with chronic diseases $^{(8,65-69)}$. This relationship, as well as the deteriorative effects of $\mathrm{SFA}^{(70,71)}$ and protective effects of $\mathrm{PUFA}^{(72)}$ and marine $n-3$ fatty acids ${ }^{(73)}$, in Chinese people then need to be re-examined in the context that dietary fat is dominated by vegetable oils. It should be analysed if Chinese people suffer different risk of chronic diseases compared with Westerners consuming more SFA and marine $n-3$ fatty acids; or compared with Japanese who consume plenty of marine $n-3$ fatty acids, PUFA and less SFA.

Our results, firstly, so far, demonstrate the trends in dietary fat and fatty acid intakes in China over nearly 15 years in the same large population of China. Besides, we showed the intakes of EPA and DHA and their trends, which are scantily reported in previous studies in China to our knowledge. In future, our research could make up for information deficiency about dietary intakes of fatty acids, which may provide a reference for related public policies in China.

In the present study, there are some limitations that must be acknowledged. The Chinese State Statistical
Office did not share their sample frame with the CHNS team when the survey was planned and implemented, although the design used extant census data as best as it could for a multilevel random sampling. As a result, our data are not nationally representative of China. In recent years, the types of food consumed in the Chinese diet have increased gradually and although the food composition databank has been updated, it cannot contain all foods. Besides, the information on fatty acids in our food composition databank is incomplete, which could also lead to underestimation of intakes of some fatty acids and even a lack of information on some specific fatty acids, such as trans-fatty acids.

\section{Conclusion}

Our study shows different dietary intakes and profile of fatty acids in Chinese adults from that reported in people of other countries. Over the years from 1997 to 2011, Chinese adults ingested more fat mainly from annually growing intakes of vegetable oils, resulting in more intake of PUFA, and less fat from low intakes of animal oils, resulting in percentage of energy from SFA being relatively low and growing slowly; and their dietary EPA and DHA intakes remained very low throughout survey period as a result of low consumptions of fish and seafood.

\section{Acknowledgements}

Acknowledgements: This research used data from the China Health and Nutrition Survey (CHNS). The authors 
Table 4 Top food sources and percentage contributions to intakes of total fat and fatty acids (\%) among participating Chinese adults aged 18 years or above $(n 19475)$ in each survey round by sex, China Health and Nutrition Survey, 1997-2011*

\begin{tabular}{|c|c|c|c|c|c|c|}
\hline & 1997 & 2000 & 2004 & 2006 & 2009 & 2011 \\
\hline \multicolumn{7}{|l|}{ Men } \\
\hline \multicolumn{7}{|l|}{ Total fat } \\
\hline Animal oils & $11 \cdot 7$ & 11.5 & $9 \cdot 3$ & 8.3 & 7.6 & $6 \cdot 3$ \\
\hline Meat and meat products & 27.9 & $27 \cdot 7$ & $26 \cdot 0$ & $27 \cdot 2$ & $26 \cdot 8$ & $25 \cdot 9$ \\
\hline Vegetable oils & 39.4 & $41 \cdot 2$ & 45.5 & 43.6 & $43 \cdot 6$ & 43.9 \\
\hline \multicolumn{7}{|l|}{ SFA } \\
\hline Animal oils & $13 \cdot 3$ & $13 \cdot 2$ & 10.9 & 9.7 & $9 \cdot 0$ & $7 \cdot 6$ \\
\hline Vegetables oils & 28.2 & 29.2 & 35.9 & 33.8 & 33.8 & 31.1 \\
\hline Meat and meat products & 34.6 & 34.6 & $32 \cdot 7$ & 34.4 & 33.7 & 33.5 \\
\hline \multicolumn{7}{|l|}{ MUFA } \\
\hline Animal oils & $12 \cdot 0$ & 11.7 & $9 \cdot 3$ & 8.3 & 7.6 & $6 \cdot 3$ \\
\hline Meat and meat products & $34 \cdot 1$ & 34.5 & $32 \cdot 0$ & 33.5 & 33.4 & $32 \cdot 2$ \\
\hline Vegetable oils & $37 \cdot 6$ & 38.6 & $43 \cdot 3$ & $41 \cdot 2$ & $40 \cdot 3$ & $40 \cdot 8$ \\
\hline \multicolumn{7}{|l|}{ PUFA } \\
\hline Animal oils & $9 \cdot 3$ & 9.4 & $7 \cdot 2$ & 6.5 & $5 \cdot 7$ & $4 \cdot 8$ \\
\hline Meat and meat products & $13 \cdot 1$ & $12 \cdot 1$ & 11.2 & 11.7 & 11.3 & $10 \cdot 7$ \\
\hline Vegetable oils & 54.9 & 58.5 & $61 \cdot 1$ & 60.5 & 60.5 & 62.6 \\
\hline \multicolumn{7}{|l|}{ EPA } \\
\hline Meat and meat products & 10.9 & 13.6 & 8.7 & 5.2 & 5.4 & $10 \cdot 1$ \\
\hline \multirow{2}{*}{\multicolumn{7}{|c|}{ DHA }} \\
\hline & & & & & & \\
\hline Meat and meat products & 11.7 & $14 \cdot 2$ & $14 \cdot 0$ & 9.0 & 9.8 & $10 \cdot 9$ \\
\hline Fish, shellfish and molluscs & 88.1 & 85.7 & $85 \cdot 8$ & 91.0 & $90 \cdot 1$ & 88.7 \\
\hline \multicolumn{7}{|l|}{$18: 1$} \\
\hline Animal oils & 11.8 & 11.6 & 8.5 & 6.9 & 5.5 & $5 \cdot 0$ \\
\hline Meat and meat products & 35.0 & 35.4 & 33.3 & 35.7 & $36 \cdot 0$ & 34.2 \\
\hline Vegetable oils & 37.9 & 39.4 & 44.0 & 41.9 & $41 \cdot 1$ & 41.6 \\
\hline \multicolumn{7}{|l|}{$18: 2$} \\
\hline Animal oils & $10 \cdot 0$ & $10 \cdot 0$ & $7 \cdot 3$ & $5 \cdot 8$ & 4.5 & 4.1 \\
\hline Meat and meat products & $11 \cdot 1$ & $10 \cdot 1$ & $9 \cdot 3$ & $10 \cdot 2$ & $10 \cdot 2$ & 9.4 \\
\hline Vegetable oils & $56 \cdot 3$ & 60.0 & 62.7 & 62.5 & 62.4 & 64.7 \\
\hline \multicolumn{7}{|l|}{$18: 3$} \\
\hline Poultry and poultry products & 2.5 & $2 \cdot 1$ & 1.9 & 1.6 & $2 \cdot 2$ & $2 \cdot 8$ \\
\hline Meat and meat products & 29.4 & 28.9 & 21.4 & 21.3 & 20.6 & 23.4 \\
\hline Vegetable oils & $32 \cdot 2$ & $36 \cdot 3$ & 50.9 & $49 \cdot 3$ & $49 \cdot 8$ & 43.5 \\
\hline Women & & & & & & \\
\hline Total fat & & & & & & \\
\hline Animal oils & $11 \cdot 3$ & $11 \cdot 7$ & $9 \cdot 0$ & $8 \cdot 0$ & $7 \cdot 2$ & $5 \cdot 8$ \\
\hline Meat and meat products & $27 \cdot 2$ & $26 \cdot 5$ & $25 \cdot 6$ & $26 \cdot 6$ & $26 \cdot 0$ & $24 \cdot 2$ \\
\hline Vegetable oils & $40 \cdot 1$ & 41.5 & $46 \cdot 1$ & 43.8 & $44 \cdot 7$ & 44.8 \\
\hline SFA & & & & & & \\
\hline Animal oils & $12 \cdot 8$ & 13.3 & $10 \cdot 6$ & $9 \cdot 2$ & 8.5 & $7 \cdot 0$ \\
\hline Vegetable oils & 28.7 & 29.4 & 36.4 & $34 \cdot 1$ & 34.7 & 31.9 \\
\hline Meat and meat products & 33.6 & 33.0 & $32 \cdot 2$ & 33.5 & $32 \cdot 7$ & 31.4 \\
\hline MUFA & & & & & & \\
\hline Animal oils & $11 \cdot 6$ & 11.9 & $9 \cdot 0$ & $8 \cdot 1$ & $7 \cdot 2$ & $5 \cdot 8$ \\
\hline Meat and meat products & 33.3 & 33.1 & 31.6 & $32 \cdot 8$ & $32 . \overline{5}$ & 30.3 \\
\hline Vegetable oils & 38.5 & $39 \cdot 2$ & 44.0 & 41.5 & 41.5 & 41.9 \\
\hline PUFA & & & & & & \\
\hline Animal oils & $9 \cdot 1$ & 9.5 & $7 \cdot 0$ & 6.4 & 5.4 & 4.3 \\
\hline Meat and meat products & $12 \cdot 6$ & 11.5 & $10 \cdot 9$ & 11.5 & $10 \cdot 8$ & 9.8 \\
\hline Vegetable oils & 55.7 & 58.9 & 61.9 & 60.4 & 61.6 & 63.1 \\
\hline EPA & & & & & & \\
\hline Meat and meat products & 7.9 & 8.8 & 6.5 & 4.8 & $5 \cdot 1$ & $8 \cdot 0$ \\
\hline Fish, shellfish and molluscs & 89.1 & 83.9 & 88.9 & 90.9 & 89.3 & 78.6 \\
\hline DHA & & & & & & \\
\hline Meat and meat products & 8.6 & $10 \cdot 3$ & 11.6 & $8 \cdot 8$ & $9 \cdot 3$ & 8.4 \\
\hline Fish, shellfish and molluscs & 91.3 & 89.7 & 88.2 & 91.2 & 90.6 & 91.3 \\
\hline $18: 1$ & & & & & & \\
\hline Animal oils & $11 \cdot 3$ & 11.7 & $8 \cdot 2$ & $6 \cdot 6$ & $5 \cdot 0$ & 4.7 \\
\hline Meat and meat products & 34.4 & 34.0 & 33.0 & 35.0 & $35 \cdot 0$ & $32 \cdot 3$ \\
\hline Vegetable oils & 38.9 & $40 \cdot 1$ & 44.6 & $42 \cdot 3$ & 42.4 & $42 \cdot 7$ \\
\hline $18: 2$ & & & & & & \\
\hline Animal oils & $9 \cdot 7$ & $10 \cdot 0$ & $7 \cdot 0$ & $5 \cdot 7$ & 4.2 & $3 \cdot 7$ \\
\hline Meat and meat products & $10 \cdot 6$ & 9.5 & 9.2 & $10 \cdot 0$ & $9 . \overline{7}$ & 8.5 \\
\hline Vegetable oils & $57 \cdot 2$ & 60.4 & 63.5 & 62.5 & 63.6 & 65.2 \\
\hline $18: 3$ & & & & & & \\
\hline Poultry and poultry products & $2 \cdot 7$ & $2 \cdot 1$ & 1.6 & 1.7 & $2 \cdot 1$ & 2.9 \\
\hline Meat and meat products & 29.4 & $27 \cdot 9$ & $20 \cdot 8$ & 20.9 & $20 \cdot 1$ & 21.7 \\
\hline Vegetable oils & 32.5 & $36 \cdot 2$ & 51.6 & 49.0 & $50 \cdot 3$ & 43.8 \\
\hline
\end{tabular}

${ }^{*} P$ for trend $<0.0001$ for all variables. 

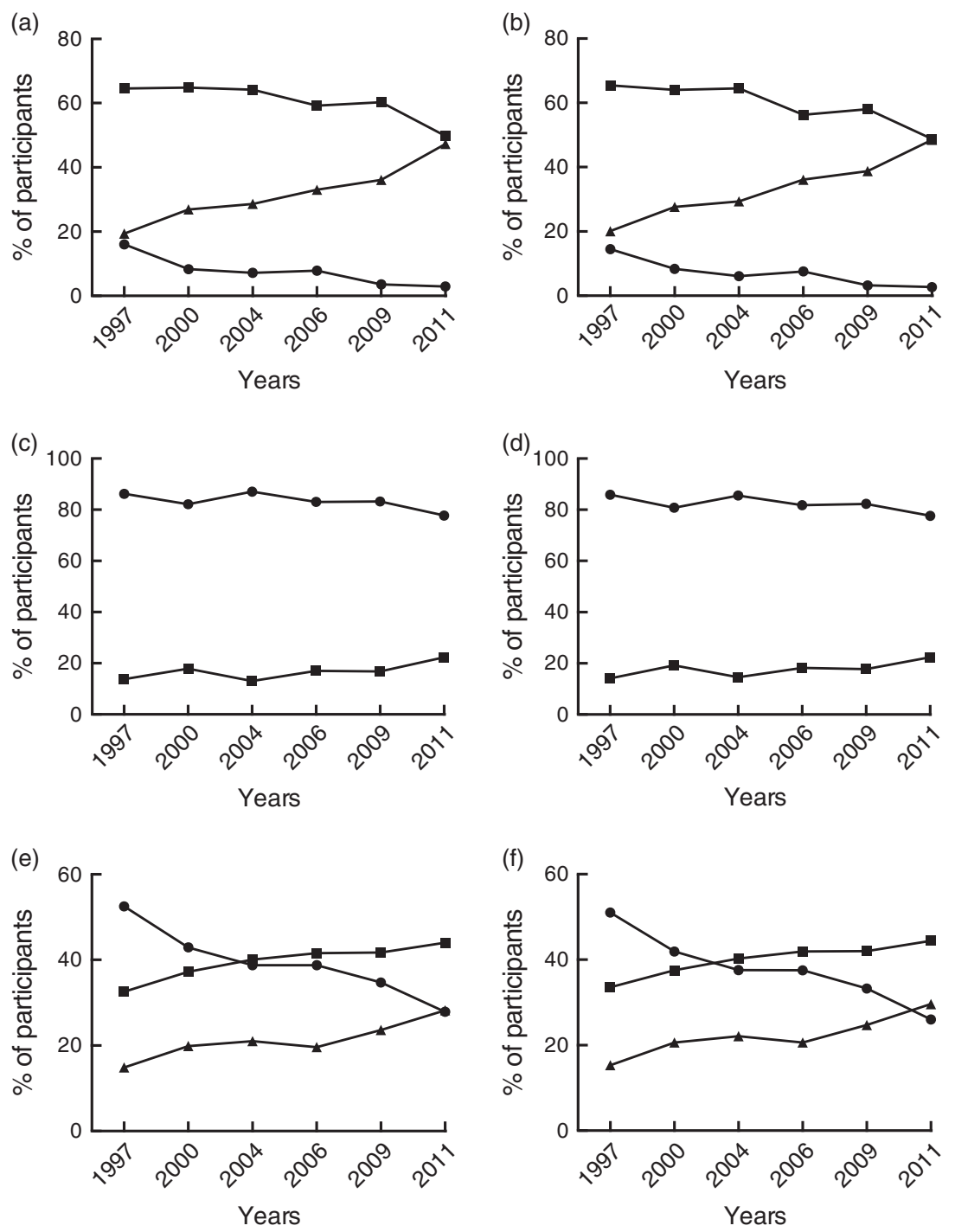

Fig. 1 Distribution of participating Chinese adults aged 18 years or above ( $n$ 19475) in different ranges of fat and fatty acid intakes (\%TE) in each survey round by sex, China Health and Nutrition Survey, 1997-2011: (a) total fat, males; (b) total fat, females

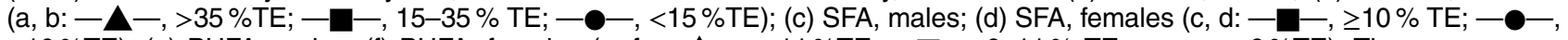
$<10 \%$ TE); (e) PUFA, males; (f) PUFA, females (e, f: $-\mathbf{A}-,>11 \%$ TE; $-\square-, 6-11 \%$ TE; $-\mathbf{-}-,<6 \%$ TE). The ranges were based on the recommendation of the $\mathrm{FAO} / \mathrm{WHO}^{(9)}$ (\% TE, percentage of total energy intake)

thank the National Institute of Nutrition and Food Safety, China Center for Disease Control and Prevention; the Carolina Population Center, University of North Carolina at Chapel Hill; the National Institutes of Health (NIH; grant numbers R01-HD30880, DK056350 and R01-HD38700); and the Fogarty International Center, NIH for financial support for the CHNS data collection and analysis files from 1989 to 2006; and both parties plus the China-Japan Friendship Hospital, Ministry of Health for support for CHNS 2009 and future surveys. Financial support: This research received no specific grant from any funding agency in the public, commercial or not-for-profit sectors. Conflict of interest: None. Authorship: X.S. conducted data collating and analysed the data, and wrote the manuscript. A.P.F designed the study, conducted data collating, scheduled the statistical analysis, and critically revised the manuscript. J.J.H. conducted data collating and advised on statistical analysis. Z.Q.L., M.H.G. and R.G. contributed to editing of the final version of the manuscript. K.J.L. critically revised the manuscript, and had the primary responsibility for the final content. All authors read and approved the final manuscript. Ethics of human subject participation: This study was conducted according to the guidelines laid down in the Declaration of Helsinki and all procedures involving human subjects/ patients were approved by the institutional review committees of the University of North Carolina at Chapel Hill and the Chinese Center for Disease Control and Prevention. Written informed consent was obtained from all subjects/patients. 


\section{References}

1. Burlingame B, Nishida C, Uauy R et al. (2009) Fats and fatty acids in human nutrition: introduction. Ann Nutr Metab $\mathbf{5 5}$, $5-7$.

2. Calder PC (2011) Fatty acids and inflammation: the cutting edge between food and pharma. Eur J Pharmacol 668, Suppl. 1, S50-S58.

3. European Food Safety Authority (2010) Scientific Opinion on Dietary Reference Values for fats, including saturated fatty acids, polyunsaturated fatty acids, monounsaturated fatty acids, trans fatty acids, and cholesterol. EFSA J 8, 1461.

4. Ericson U, Hellstrand S, Brunkwall L et al. (2015) Food sources of fat may clarify the inconsistent role of dietary fat intake for incidence of type 2 diabetes. Am J Clin Nutr $\mathbf{1 0 1}$, 1065-1080.

5. Freedland SJ (2013) Dietary fat and reduced prostate cancer mortality: does the type of fat matter? JAMA Intern Med $\mathbf{1 7 3}$ $1326-1327$.

6. Vafeiadou K, Weech M, Sharma V et al. (2012) A review of the evidence for the effects of total dietary fat, saturated, monounsaturated and $n-6$ polyunsaturated fatty acids on vascular function, endothelial progenitor cells and microparticles. Br J Nutr 107, 303-324.

7. Hooper L, Summerbell CD, Higgins JP et al. (2001) Dietary fat intake and prevention of cardiovascular disease: systematic review. BMJ 322, 757-763.

8. Hu FB, Manson JE \& Willett WC (2001) Types of dietary fat and risk of coronary heart disease: a critical review. $J \mathrm{Am}$ Coll Nutr 20, 5-19.

9. Food and Agriculture Organization of the United Nations (2010) Fats and Fatty Acids in Human Nutrition. Report of an Expert Consultation, 10-14 November 2008, Geneva. FAO Food and Nutrition Paper no. 91, Rome: FAO.

10. McGuire S (2011) US Department of Agriculture and US Department of Health and Human Services, Dietary Guidelines for Americans, 2010, 7th Edition. Washington, DC: US Government Printing Office; January 2011. Adv Nutr 2, 293-294.

11. Department of Health, Committee on Medical Aspects of Food Policy (1991) Dietary Reference Values for Food Energy and Nutrients for the United Kingdom: Report of the Panel on Dietary Reference Values of the Committee on Medical Aspects of Food Policy. Report on Health and Social Subjects no. 41. London: HMSO.

12. Chinese Society of Nutrition (2014) Chinese Dietary Reference Intakes (2013 Edition), 1 ed. Beijing: Science Press.

13. Sasaki S (2008) Dietary Reference Intakes (DRIs) in Japan. Asia Pac J Clin Nutr 17, Suppl. 2, 420-444.

14. Wang D, He Y, Li Y et al. (2011) Dietary patterns and hypertension among Chinese adults: a nationally representative cross-sectional study. BMC Public Health 11, 925.

15. Li Y, He Y, Lai J et al. (2011) Dietary patterns are associated with stroke in Chinese adults. J Nutr 141, 1834-1839.

16. Batis C, Sotres-Alvarez D, Gordon-Larsen P et al. (2014) Longitudinal analysis of dietary patterns in Chinese adults from 1991 to 2009. Br J Nutr 111, 1441-1451.

17. Zhai F, Wang H, Du S et al. (2009) Prospective study on nutrition transition in China. Nutr Rev 67, Suppl. 1, S56-S61.

18. Wang Z, Zhai F, Du S et al. (2008) Dynamic shifts in Chinese eating behaviors. Asia Pac J Clin Nutr 17, 123-130.

19. Wang J, Zhang D, Xiao Y et al. (2003) Prevalence of hypertension and the relationship between dietary pattern and hypertension in rural middle-aged and elderly in HeNan Province. Wei Sheng Yan Jiu 32, 46-48 (in Chinese).

20. Villegas R, Yang G, Gao YT et al. (2010) Dietary patterns are associated with lower incidence of type 2 diabetes in middle-aged women: the Shanghai Women's Health Study. Int J Epidemiol 39, 889-899.
21. Sun J, Buys NJ \& Hills AP (2014) Dietary pattern and its association with the prevalence of obesity, hypertension and other cardiovascular risk factors among Chinese older adults. Int J Environ Res Public Health 11, 3956-3971.

22. Wang CN, Liang Z, Wei P et al. (2002) Changes in dietary patterns and certain nutrition-related diseases in urban and rural residents of Jiangsu Province, China, during the 1990s. Biomed Environ Sci: BES 15, 271-276.

23. Zhai FY, Wang HJ, Du SF et al. (2003) The changing trend of dietary fat intake of Chinese population - an eight provinces case study in China. Acta Nutr Sinica 25, 230-234.

24. Popkin BM, Du S, Zhai F et al. (2010) Cohort Profile: The China Health and Nutrition Survey - monitoring and understanding socio-economic and health change in China, 1989-2011. Int J Epidemiol 39, 1435-1440.

25. Zhang B, Zhai FY, Du SF et al. (2014) The China Health and Nutrition Survey, 1989-2011. Obes Rev 15, Suppl. 1, 2-7.

26. Jones-Smith JC \& Popkin BM (2010) Understanding community context and adult health changes in China: development of an urbanicity scale. Soc Sci Med 71, 1436-1446.

27. Su C, Jia X, Wang Z et al. (2014) Trends in dietary cholesterol intake among Chinese adults: a longitudinal study from the China Health and Nutrition Survey, 1991-2011. BMJ Open 5, e007532.

28. Institute for Nutrition and Food Hygiene of the Chinese Academy of Preventive Medicine (1991) Food Composition Table. Beijing: People's Medical Publishing House.

29. Institute for Nutrition and Food Safety of the Chinese Center for Disease Control and Prevention (2002) China Food Composition Table (2002). Beijing: Peking University Medical Press.

30. Institute for Nutrition and Food Safety of the Chinese Center for Disease Control and Prevention (2005) China Food Composition Table (2004). Beijing: Peking University Medical Press.

31. Elmadfa I \& Kornsteiner M (2009) Dietary fat intake - a global perspective. Ann Nutr Metab 54, Suppl. 1, 8-14.

32. Linseisen J, Welch AA, Ocke $M$ et al. (2009) Dietary fat intake in the European Prospective Investigation into Cancer and Nutrition: results from the 24-h dietary recalls. Eur J Clin Nutr 63, Suppl. 4, S61-S80.

33. Eilander A, Harika RK \& Zock PL (2015) Intake and sources of dietary fatty acids in Europe: are current population intakes of fats aligned with dietary recommendations? Eur J Lipid Sci Technol 117, 1370-1377.

34. Harika RK, Eilander A, Alssema M et al. (2013) Intake of fatty acids in general populations worldwide does not meet dietary recommendations to prevent coronary heart disease: a systematic review of data from 40 countries. Ann Nutr Metab 63, 229-238.

35. Vadiveloo M, Scott M, Quatromoni P et al. (2014) Trends in dietary fat and high-fat food intakes from 1991 to 2008 in the Framingham Heart Study participants. Br J Nutr 111, 724-734.

36. Li K, McNulty BA, Tiernery AM et al. (2016) Dietary fat intakes in Irish adults in 2011: how much has changed in 10 years? Br J Nutr 115, 1798-1809.

37. Sioen I, Vyncke K, de Maeyer M et al. (2013) Dietary intake and food sources of total and individual polyunsaturated fatty acids in the Belgian population over 15 years old. Lipids 48, 729-738.

38. Elmadfa I, Meyer A, Nowak V et al. (2009) European Nutrition and Health Report 2009. Forum Nutr 62, 1-405.

39. Honors MA, Harnack LJ, Zhou X et al. (2014) Trends in fatty acid intake of adults in the Minneapolis-St Paul, MN Metropolitan Area, 1980-1982 through 2007-2009. J Am Heart Assoc 3, e001023.

40. Micha R, Khatibzadeh S, Shi P et al. (2014) Global, regional, and national consumption levels of dietary fats and oils in 
1990 and 2010: a systematic analysis including 266 countryspecific nutrition surveys. BMJ 350, 584-584.

41. Mente A, de Koning L, Shannon HS et al. (2009) A systematic review of the evidence supporting a causal link between dietary factors and coronary heart disease. Arch Intern Med 169, 659-669.

42. Caballero B \& Popkin B (2002) The Nutrition Transition: Diet and Disease in the Developing World. London: Academic Press.

43. Krauss RM, Eckel RH, Howard B et al. (2000) AHA Scientific Statement. AHA Dietary Guidelines. Revision 2000: a statement for healthcare professionals from the nutrition committee of the American Heart Association. J Nutr 131, $132-146$.

44. Chen XS, Wen ZM \& Lin H (1998) Dietary fat consumption and non-communicable chronic diseases in China. Asia Pac J Clin Nutr 7, 293-296.

45. Wang Y, Mi J, Shan XY et al. (2007) Is China facing an obesity epidemic and the consequences? The trends in obesity and chronic disease in China. Int J Obes (Lond) 31, 177-188.

46. Zhang J, Meng L-P, Jiang Y-R et al. (2009) The dietary fatty acids intakes and their food sources among Chinese adults. Acta Nutr Sinica 31, 424-427.

47. Fu J, Wang Z \& Wang B (2006) Transitions of food groups and nutrients in the northeast of China: a 3-year-interval's follow-up study. Econ Geogr 2, 1-8.

48. Matsumura Y (2001) Nutrition trends in Japan. Asia Pac J Clin Nutr 10, Suppl, S40-S47.

49. Japanese Ministry of Health Labour and Welfare (2014) National Health and Nutrition Survey (in Japanese). http:// www.mhlw.go.jp/bunya/kenkou/kenkou_eiyou_chousa.html (accessed August 2016).

50. US Centers for Disease Control and Prevention (2016) National Health and Nutrition Examination Survey. http:// www.cdc.gov/nchs/nhanes/index.htm (accessed August 2016).

51. Hulshof KF, van Erp-Baart MA, Anttolainen M et al. (1999) Intake of fatty acids in western Europe with emphasis on trans fatty acids: the TRANSFAIR Study. Eur J Clin Nutr $\mathbf{5 3}$, 143-157.

52. Choudhary M, Grover K \& Javed M (2014) Nutritional profiles of urban and rural men of Punjab with regard to dietary fat intake. Ecol Food Nutr 53, 436-452.

53. Maruyama C, Nakano R, Shima M et al. (2016) Effects of a Japan diet intake program on metabolic parameters in middle-aged men: a pilot study. J Atheroscler Thromb 24, 393-401.

54. Pot GK, Prynne CJ, Roberts C et al. (2012) National Diet and Nutrition Survey: fat and fatty acid intake from the first year of the rolling programme and comparison with previous surveys. Br J Nutr 107, 405-415.

55. Zhai F-Y, He Y-N, Ma G-S et al. (2005) Study on the current status and trend of food consumption among Chinese population. Chin J Epidemiol 26, 485-488 (in Chinese).

56. Li LM, Rao KQ, Kong LZ et al. (2005) A description on the Chinese national nutrition and health survey in 2002. Chin J Epidemiol 26, 478-484 (in Chinese).

57. Nation Bureau of Statistics of China (2012) National data: indicators of people's lives (in Chinese). http://data. stats.gov.cn/easyquery.htm? $\mathrm{cn}=\mathrm{C} 01 \& \mathrm{zb}=\mathrm{A} 0 \mathrm{~A} 0 \mathrm{H} \& \mathrm{sj}=2014$ (accessed August 2016).
58. Ervin RB, Wright JD, Wang CY et al. (2004) Dietary intake of fats and fatty acids for the United States population: 1999-2000. Adv Data issue 348, 1-6.

59. Sergeant S, Hugenschmidt CE, Rudock ME et al. (2012) Differences in arachidonic acid levels and fatty acid desaturase (FADS) gene variants in African Americans and European Americans with diabetes or the metabolic syndrome. Br J Nutr 107, 547-555.

60. Simopoulos AP (2006) Evolutionary aspects of diet, the omega-6/omega-3 ratio and genetic variation: nutritional implications for chronic diseases. Biomed Pharmacother 60, 502-507.

61. Li SW, Lin K, Ma P et al. (2013) FADS gene polymorphisms confer the risk of coronary artery disease in a Chinese Han population through the altered desaturase activities: based on high-resolution melting analysis. PLoS One $\mathbf{8}$, e55869.

62. Skeaff CM \& Miller J (2009) Dietary fat and coronary heart disease: summary of evidence from prospective cohort and randomised controlled trials. Ann Nutr Metab 55, 173-201.

63. Mente A, De KL, Shannon HS et al. (2009) A systematic review of the evidence supporting a causal link between dietary factors and coronary heart disease. Arch Intern Med 169, 659-669.

64. National Health and Family Planning Commission (2015) 2015 report on Chinese resident's chronic disease and nutrition (in Chinese). http://www.nhfpc.gov.cn/zhuz/xwfb/ 201506/6b4c0f873c174ace9f57f11fd4f6f8d9.shtml (accessed August 2016).

65. Voon PT, Ng TK, Lee VK et al. (2015) Virgin olive oil, palm olein and coconut oil diets do not raise cell adhesion molecules and thrombogenicity indices in healthy Malaysian adults. Eur J Clin Nutr 69, 712-716.

66. Voon PT, Ng TK, Lee VK et al. (2011) Diets high in palmitic acid (16:0), lauric and myristic acids $(12: 0+14: 0)$, or oleic acid $(18: 1)$ do not alter postprandial or fasting plasma homocysteine and inflammatory markers in healthy Malaysian adults. Am J Clin Nutr 94, 1451-1457.

67. Vega-Lopez S, Ausman LM, Jalbert SM et al. (2006) Palm and partially hydrogenated soybean oils adversely alter lipoprotein profiles compared with soybean and canola oils in moderately hyperlipidemic subjects. Am J Clin Nutr 84, $54-62$.

68. Fattore E, Bosetti C, Brighenti F et al. (2014) Palm oil and blood lipid-related markers of cardiovascular disease: a systematic review and meta-analysis of dietary intervention trials. Am J Clin Nutr 99, 1331-1350.

69. Willett WC (2011) The great fat debate: total fat and health. J Am Diet Assoc 111, 660-662.

70. Summers LK, Fielding BA, Bradshaw HA et al. (2002) Substituting dietary saturated fat with polyunsaturated fat changes abdominal fat distribution and improves insulin sensitivity. Diabetologia 45, 369-377.

71. Söderström L, Rosenblad A, Adolfsson ET et al. (2015) A high energy intake from dietary fat among middle-aged and older adults is associated with increased risk of malnutrition 10 years later. Br J Nutr 114, 915-923.

72. Sanders TA (2014) Protective effects of dietary PUFA against chronic disease: evidence from epidemiological studies and intervention trials. Proc Nutr Soc 73, 73-79.

73. Willatts P, Forsyth S, Agostoni C et al. (2013) Effects of long-chain PUFA supplementation in infant formula on cognitive function in later childhood. Am J Clin Nutr 98, issue 2, 536S-542S. 